\title{
Prevalence and associated factors of undiagnosed atrial fibrillation among end- stage renal disease patients on maintenance haemodialysis: a cross- sectional study
}

Izzat AlAwwa ${ }^{*}$, Reham Al-Hindi², Nadeen Alfraihat ${ }^{2}$, Ahmad Obeid $^{2}$, Sarah Ibrahim², Shatha Jallad ${ }^{3}$, Ahmad Al-Awwa ${ }^{4}$ and Akram Saleh ${ }^{1}$

\begin{abstract}
Background: Atrial fibrillation (AF) is the most prevalent sustained arrhythmia worldwide and it aggravates cardiovascular morbidity and mortality; however, this is largely under-diagnosed. Moreover, among end-stage renal disease patients on haemodialysis, AF is substantially more common and serious. The researchers conducted this study to assess the prevalence of, and the factors correlated with AF in Jordanian haemodialysis patients.

Methods: In a cross-sectional analysis conducted from October 2018 to February 2019 in four tertiary hospitals, the researchers enrolled all consenting patients aged 18 years or older who were on haemodialysis for at least three months prior to the study. We screened for AF clinically by pulse palpation, precordial auscultation, by an automated blood pressure monitor and an electrocardiogram. The researchers reported qualitative variables as counts and frequencies, while continuous variables were summarised using the mean or median where necessary. We used multiple logistic regression with backward selection to identify independent risk factors of AF.

Results: A total of 231 patients were enrolled; mean age was $54.8 \pm 15.6$ years (from 20 to 86 ), and $44.3 \%$ of them were women. The prevalence of AF was found to be $7.8 \%(95 \% \mathrm{Cl}, 4.8-12.2)$, with no gender disparity. Age (adjusted odds ratio $[\mathrm{AOR}]=1.05 ; 95 \% \mathrm{Cl}, 1.01-1.10 ; p=0.031)$, history of ischaemic heart disease $(\mathrm{AOR}=3.74 ; 95 \%$ $\mathrm{Cl}, 1.09-12.34 ; p=0.033)$, history of smoking ( $\mathrm{AOR}=0.15 ; 95 \% \mathrm{Cl}, 0.02-0.60 ; p=0.019)$, and low interdialytic weight gain $(A O R=0.50: 95 \% \mathrm{Cl}, 0.25-0.91 ; p=0.031$ ) were independently correlated to $\mathrm{AF}$.

\footnotetext{
* Correspondence: izzat55@gmail.com

'School of medicine, the University of Jordan, PO Box 954180, Amman

11954, Jordan

Full list of author information is available at the end of the article
}

C C The Author(s). 2020 Open Access This article is licensed under a Creative Commons Attribution 4.0 International License, which permits use, sharing, adaptation, distribution and reproduction in any medium or format, as long as you give appropriate credit to the original author(s) and the source, provide a link to the Creative Commons licence, and indicate if changes were made. The images or other third party material in this article are included in the article's Creative Commons licence, unless indicated otherwise in a credit line to the material. If material is not included in the article's Creative Commons licence and your intended use is not permitted by statutory regulation or exceeds the permitted use, you will need to obtain permission directly from the copyright holder. To view a copy of this licence, visit http://creativecommons.org/licenses/by/4.0/. The Creative Commons Public Domain Dedication waiver (http://creativecommons.org/publicdomain/zero/1.0/) applies to the data made available in this article, unless otherwise stated in a credit line to the data. 


\begin{abstract}
(Continued from previous page)
Conclusions: The prevalence of AF among patients on maintenance haemodialysis is high, but largely undiagnosed. AF is generally associated with advancing age, history of ischaemic heart disease, lower interdialytic weight gain, and history of smoking. We suggest routine check-up of AF in this high-risk group of patients as anticoagulant therapy if indicated may prevent serious complications. However, there is a need for large-scale cohort studies and for the creation of regional chronic kidney disease and dialysis registries in the Middle East region.
\end{abstract}

Keywords: Atrial fibrillation, Nonvalvular, Arrhythmia, End stage renal disease, Haemodialysis, Stroke, Cardiovascular risk, Subclinical, Anticoagulation

\section{Introduction}

Atrial fibrillation (AF) is the commonest cardiac arrhythmia, and a global public health problem associated with high rates of hospitalisation, disability, and complications such as heart failure, cardiomyopathy, and cardio-embolic events like stroke [1-4]. The incidence and prevalence of AF have been on a rise globally especially in high-income European countries $[1,5]$. In fact, about 33.5 million persons or $0.5 \%$ of the world's population is estimated to have AF with age-adjusted prevalence rates of 596.2 and 373.1 per 100,000 in males and females, respectively. These prevalence rates in both genders were higher than previous values of 569.5 and 359.9 per 100,000 population reported in 1990 for men and women, respectively [5]. A similar increase in disability and mortality due to AF was also noted [5]. This rising prevalence of $\mathrm{AF}$ is in sync with the increasing cardiometabolic risk factors such as obesity, hypertension, diabetes, and an increasing population of elders globally [1].

It is estimated that between 11 and $13 \%$ of the world's population is affected by chronic kidney disease (CKD); with the prevalence of stage 5 CKD estimated at about $0.1 \%$ [6]. Worsening kidney function has been associated with the risk of cardiovascular complications especially among patients on haemodialysis [7-9]. Cardiovascular complications significantly contribute up to $50 \%$ of allcause mortality among patients with end stage renal disease (ESRD) on haemodialysis in the United States [10], with sudden cardiac death, arrhythmia, heart failure, and coronary artery disease reported as the main cardiovascular causes of mortality [8]. During haemodialysis, rapid fluctuations in haemodynamics and electrolyte concentrations, as well as the induction of hypoxemia increases the likelihood of developing arrhythmias [11]. Also, the incidence of $\mathrm{AF}$ increases after dialysis due to increase in cardiac dimensions [12-14]. Although arrhythmias developed during haemodialysis are mostly brief, asymptomatic, and self-limiting, they have been independently associated with higher mortality and cardiovascular events $[15,16]$. The incidence of $\mathrm{AF}$ in patients with ESRD on dialysis varies between 6.6 to $20 \%$ and is 2 to 3 times higher than in the general population [17-20]. Furthermore, AF in patients with ESRD is associated with higher morbidity and up to $50 \%$ mortality rate in a cohort of patients with ESRD undergoing haemodialysis $[19,21,22]$. Despite the significant impact of AF in patients with ERSD, this remains a neglected topic in the scientific literature, especially in the Middle East in general and Jordan in particular, as a detailed PubMed search revealed no study on the prevalence, incidence, or mortality of AF in patients with ESRD in the region.

This study sought to evaluate the prevalence and factors associated with previously undiagnosed AF among patients with ESRD on maintenance haemodialysis. The information from the study is vital to enlighten practice in the Middle East and add to the limited literature on topic globally.

\section{Methods}

\section{Study design and setting}

This was a cross-sectional analysis conducted from October 2018 to February 2019, in four haemodialysis centres in Amman. Each dialysis unit serves about 50 to 150 patients and is managed by a nephrologist.

\section{Study population and sample size}

All patients with ESRD undergoing haemodialysis were screened for eligibility and then invited to take part in the study. The researchers enrolled all consenting participants aged 18 years or older, diagnosed with ESRD and had received haemodialysis for at least three months prior to the study. We excluded patients with a previous diagnosis of arrhythmia or AF, and any psychiatric, psychological, or debilitating disorder which could prevent the patients from either being interviewed or understanding the questions.

Using the Cochrane's formula below, we calculated a minimum acceptable sample size (n) of 167 participants.

$$
n=\frac{Z^{2} P(1-P)}{d^{2}}
$$

$\mathrm{Z}=\mathrm{Z}$ statistics $=1.96$ for a $95 \%$ confidence interval $(\mathrm{CI})$; $\mathrm{p}=$ prevalence of subclinical AF among patients with 
ESRD on dialysis $=0.124[18]$; and $d=$ margin of error which was considered to be $5 \%$ for this study.

Participants were consecutively enrolled in the study.

\section{Ethical consideration}

The study protocol was approved by the ethical review boards (IRB) of the participating hospitals. All patients signed an informed written consent form after being explained the details of the research, its procedure, the potential benefits and harm, and their questions were satisfactorily answered.

\section{Study procedure and data collection}

Patients were interviewed by trained final year medical students using a pre-designed questionnaire to collect information on the general demographic information (e.g. age, gender, marital status, and occupation), past medical history (e.g. Family history of hypertension, history of diabetes mellitus, and ischaemic heart disease), and dialysis related information (e.g. duration of dialysis, dialysis access and number of sessions per week). Information on the patient's drugs and results of the laboratory tests were also collected from the patient's medical file. The patient's body mass index was computed using the patient's weight (measured in the nearest $10 \mathrm{~g}$ ) and height (in centimetres). An automated blood pressure (BP) monitor with irregular heartbeat detector (Omron M6, Omron Healthcare Co. Ltd., Japan) was used to detect the presence of irregular heartbeat during BP recording. This device has been clinically validated for detecting AF during blood pressure recording with a sensitivity of $98.7 \%$ [18].

At baseline, prior to haemodialysis, we screened all patients for AF by palpating their pulse and auscultating their heart to check for irregularities using the automated BP monitor and a 12-lead electrocardiogram (ECG). The patients' BP and pulse were also monitored during dialysis using the automated BP monitor. An irregular heartbeat sign on the device screen would flash if an irregular heartbeat was detected. If the sign flashed, the $\mathrm{BP}$ was remeasured after five minutes to confirm the presence of the sign. A second ECG was obtained if the sign persisted. Only patients with an episode of AF on 12-lead ECG were confirmed to have AF. All ECGs were performed by trained final year medical students, and the ECG findings were interpreted blindly by a consultant cardiologist in two separate sessions.

\section{Statistical analysis}

We used Microsoft Excel 2010 spreadsheets for data entry and curation, and the statistical software R (version 3.5.3, The $\mathrm{R}$ Foundation for statistical computing, Vienna, Austria) for data analysis. We reported qualitative variables as counts and proportions while we summarized quantitative variables as means and medians with their corresponding standard deviation (SD) and interquartile range (IQR), respectively. Histograms and probability distribution plots were used to visually assess continuous variables for normality and presence of outliers. The Fisher's exact test was used to compare categorical variables, while the student t-test or MannWhitney $\mathrm{U}$ test was used to compare continuous and categorical variables as appropriate. We determined independent factors correlated with AF using multiple logistic regression analysis utilizing backward elimination method [23]. Only variables with $p$-values less than 0.1 on bivariate analysis, with the exception of gender, were evaluated using backward elimination method and based on the Akaike information criterion (AIC) for final inclusion in the multiple regression model [23]. Lower AIC signified a better model. The best model (based on the AIC) constituted of the variables: age, history of smoking, average weight gain during dialysis, history of ischaemic heart disease, and diastolic blood pressure before dialysis. Two-tailed $p$-values below 0.05 were considered statistically significant.

\section{Results \\ Description of the study population}

Collectively, we enrolled 231 participants in this study. Only one candidate was excluded because of previous diagnosis of AF. The mean age of the participants was 54.8 years $(\mathrm{SD}=15.6)$ and participants who developed atrial fibrillation were significantly older than their counterparts without atrial fibrillation $(p<0.001)$, Table 1 . About $44.2 \%$ of the participants were females and $71.7 \%$ were married. About $85 \%$ were Jordanians.

Three-quarters of the participants were hypertensive, almost 40 and $30 \%$ had diabetes mellitus or dyslipidemia, $14 \%$ had ischaemic heart disease while the presence of vulvulopathies were rare, Table 2.

On an average, the participants had three sessions of dialysis per week, with each session lasting four hours. Over three-quarters of the route of access for dialysis was an arteriovenous fistula. Participants gained an average of $3.1 \mathrm{~kg}$ in between the dialysis sessions, Table 3 .

About 90,70 , and $40 \%$ of the participants were on calcium, alpha 1 hydroxylase vitamin $\mathrm{D}$, and beta-blockers. About 23\% were on furosemide, Table 4.

Prevalence of atrial fibrillation in the study population Eighteen out of the 231 participants were diagnosed with atrial fibrillation giving a prevalence of $7.8 \%(95 \% \mathrm{CI}$, $4.8-12.2)$ with no gender disparity $(p=0.453)$, Table 1.

\section{Factors associated with atrial fibrillation}

The final multiple regression model predicted age (adjusted odds ratio $[\mathrm{AOR}]=1.05,95 \% \mathrm{CI}, 1.01-1.10, p=$ $0.031)$, ischaemic heart disease $(\mathrm{AOR}=3.74,95 \% \mathrm{CI}$, 
Table 1 Sociodemographic data of the study population

\begin{tabular}{|c|c|c|c|c|}
\hline Variables & Total $N=231(100.0 \%)$ & AF $N=18(7.8 \%)$ & No AF $N=213(92.2 \%)$ & $p$-value \\
\hline Mean age in years $( \pm S D)$ & $54.8 \pm 15.6$ & $65.9 \pm 15.6$ & $53.9 \pm 10.5$ & $<0.001^{*}$ \\
\hline Gender & & & & 0.453 \\
\hline Females & $102(44.2)$ & $10(55.6)$ & $92(43.2)$ & \\
\hline Males & $129(55.8)$ & $8(44.4)$ & $121(56.8)$ & \\
\hline Marital Status & & & & 0.092 \\
\hline Married & $165(71.7)$ & $16(88.9)$ & $149(70.0)$ & \\
\hline Single & $65(28)$ & $2(11.1)$ & $64(30.0)$ & \\
\hline Nationality & & & & 0.674 \\
\hline Jordanian & $200(86.6)$ & $15(83.3)$ & $185(86.9)$ & \\
\hline Others & $31(13.4)$ & $3(16.7)$ & $28(13.1)$ & \\
\hline Body mass index $\left(\mathrm{kg} / \mathrm{m}^{2}\right) *( \pm S D)$ & $26.0 \pm 5.6$ & $26.2 \pm 5.6$ & $26.0 \pm 5.6$ & 0.914 \\
\hline
\end{tabular}

${ }^{*}$ Mean $\pm \mathrm{SD} ; \mathrm{AF}=$ atrial fibrillation; $\mathrm{SD}=$ standard deviation

$1.09-12.34, p=0.033$ ), history of smoking (AOR $=0.15$, 95\% CI, 0.02-0.60, $p=0.019)$, and low interdialytic weight gain $(\mathrm{AOR}=0.50,95 \% \mathrm{CI}, 0.25-0.91, p=0.031$ ) as independent factors associated with the occurrence of atrial fibrillation with a very good accuracy $(\mathrm{C}$ statistics $=$ $82.2 \%)$, Table 5 . As shown by the Nagelkerke pseudoR2 value, $25.4 \%$ of the variation in the outcome variable was explained by the aforementioned independent variables.

The model was also a good fit for our data as was revealed by a non-significant Hosmer-Lemeshow test (Chi-square $=3.31, p=0.913$ ), Table 5 . Figures 1 and 2 display a good fit between the predicted data for both cases of atrial fibrillation and non-atrial fibrillation cases.

\section{Discussion}

We sought to evaluate the prevalence and factors associated with atrial fibrillation among ESRD on maintenance chronic haemodialysis. The high prevalence of $7.8 \%$ was linked to increasing age, history of smoking, history of ischaemic heart disease and lower interdialytic weight gain with a very good accuracy.

Very few studies have evaluated the prevalence of subclinical AF among ERSD patients on maintenance haemodialysis. The prevalence of AF in this study is similar to rates of 7.7 and $8.0 \%$ reported by Konigsbrugge et al., 2017 [17] and Winkelmayer et al., 2011 [20] though much lower than those reported by Vazquez et al., in 2009 [18]. The lower prevalence in our study compared to that of Vasquez and colleagues is most likely due to the younger age of participants in our study as Vazquez et al. only recruited elderly participants (65 years or older). In addition, this could also be due to methodological differences as these studies were based on medical records contrary to our study as previously known cases of AF were excluded and we also depended on direct patient contact and an electrocardiogram to

Table 2 Past Medical History of the participants

\begin{tabular}{|c|c|c|c|c|}
\hline Variables & Total $N=231(100.0 \%)$ & AF N $=18(7.8 \%)$ & No AF N = $213(92.2 \%)$ & $\overline{p \text {-value }}$ \\
\hline Hypertension, Yes (\%) & $174(75.3)$ & $15(83.3)$ & $159(74.6)$ & 0.412 \\
\hline Diabetes mellitus, Yes (\%) & $91(39.4)$ & $10(55.6)$ & $81(38.0)$ & 0.143 \\
\hline Dyslipidaemia, Yes (\%) & $68(29.9)$ & $6(33.3)$ & $63(29.6)$ & 0.738 \\
\hline Ischemic heart disease, Yes (\%) & $33(14.3)$ & $6(33.3)$ & $27(12.7)$ & $0.016^{*}$ \\
\hline Heart failure, Yes (\%) & $34(14.7)$ & $5(27.8)$ & $29(13.6)$ & 0.103 \\
\hline Valvulopathy, Yes (\%) & $4(1.7)$ & $1(5.6)$ & $3(1.4)$ & 0.195 \\
\hline Family history of dialysis, Yes (\%) & $48(20.8)$ & $3(16.7)$ & $45(21.1)$ & 0.654 \\
\hline History of smoking, Yes (\%) & $87(37.7)$ & $2(11.1)$ & $85(39.9)$ & $0.015^{*}$ \\
\hline Consume alcohol, Yes (\%) & $5(2.2)$ & $0(0.0)$ & $5(2.4)$ & 0.509 \\
\hline Tea intake, Yes (\%) & $182(79.1)$ & $16(88.9)$ & $166(78.3)$ & 0.289 \\
\hline Number of glasses of tea per week ${ }^{\&}$ & $7(2-14)$ & $10.5(7.0-19.3)$ & $7.0(1-14)$ & 0.140 \\
\hline Coffee intake, Yes (\%) & $167(72.6)$ & $11(61.1)$ & $156(73.6)$ & 0.388 \\
\hline Number of cups of coffee per week ${ }^{\&}$ & $7(1-14)$ & $7(0-7)$ & $3(0-14)$ & 0.153 \\
\hline
\end{tabular}

${ }^{\&}$ Median (interquartile range); ${ }^{*}$ Meaan $\pm \mathrm{SD} ; \mathrm{AF}=$ atrial fibrillation 
Table 3 Haemodialysis variables of participants

\begin{tabular}{|c|c|c|c|c|}
\hline Variables & Total N = 231 (100.0\%) & AF N = $18(7.8 \%)$ & No AF N = $213(92.2 \%)$ & $p$-value \\
\hline Duration of dialysis (in hours) ${ }^{\&}$ & $4(3.0-4.0)$ & $3.5(3.0-4.0)$ & $4.0(3.0-4.0)$ & 0.260 \\
\hline Number of sessions per week ${ }^{\&}$ & $3(3-3)$ & $3(3-3)$ & $3(3-3)$ & 0.230 \\
\hline Dialysis access type & & & & 0.445 \\
\hline Arteriovenous fistula Yes (\%) & $177(76.6)$ & $12(66.7)$ & $161(77.4)$ & \\
\hline Arteriovenous graft Yes (\%) & $3(1.3)$ & $0(0.0)$ & $3(1.4)$ & \\
\hline Central dialysis catheter Yes (\%) & $51(22.1)$ & $6(33.3)$ & $44(21.2)$ & \\
\hline \multicolumn{5}{|l|}{ Pre-dialysis } \\
\hline Average Systolic BP (in mmHg)* & $133 \pm 28.4$ & $126.9 \pm 34.5$ & $133.6 \pm 27.8$ & 0.436 \\
\hline Average Diastolic BP (in $\mathrm{mmHg})^{*}$ & $78.3 \pm 13.5$ & $71.3 \pm 13.5$ & $78.9 \pm 13.4$ & $0.034^{*}$ \\
\hline \multicolumn{5}{|l|}{ Post dialysis } \\
\hline Average SBP (in $\mathrm{mmHg})^{*}$ & $120.5 \pm 28.6$ & $121.0 \pm 32.4$ & $120.5 \pm 28.3$ & 0.950 \\
\hline Average DBP (in $\mathrm{mmHg})^{*}$ & $73.3 \pm 14.1$ & $73.2 \pm 14.5$ & $73.3 \pm 14.1$ & 0.967 \\
\hline Average weight gain during dialysis (in $\mathrm{kg}) *( \pm \mathrm{SD}$ ) & $3.1 \pm 1.0$ & $2.6 \pm 1.0$ & $3.1 \pm 1.0$ & $0.031^{*}$ \\
\hline
\end{tabular}

\&Median (interquartile range); *Mean $\pm \mathrm{SD} ; \mathrm{AF}=$ atrial fibrillation; $\mathrm{BP}=$ blood pressure; $\mathrm{SD}=$ standard deviation

establish the diagnosis of subclinical AF. Most of our participants were within their fifth and sixth decades of life. This is a striking finding as it is the peak age for economic productivity and may therefore have a negative impact on the socioeconomic burden of ESRD in Jordan.

In the current study, age, history of smoking, history of ischaemic heart disease, and low interdialytic weight gain explained up to $25.4 \%$ of the total variability in the outcome. Age has been consistently reported in literature to be a strong predictor of $\mathrm{AF}[17,18,20,24]$. Aging is a normal physiological process which increases the individual's risk of cardiovascular diseases such as hypertension, ischaemic heart diseases, and other comorbidities [24, 25]. These diseases are major risk factors for stroke. However, advanced age can directly cause AF even though the mechanism is still unclear [24]. However, existing theories suggest that advancing age leads to AF through atrial fibrosis, which is a major cause of atrial fibrillation [26].

Additionally, ischaemic heart failure is a wellestablished risk factor for AF [27]. A previous ischaemic heart disease will lead to cardiac remodeling, which predisposes the patient to aberrant intra-atrial conduction and consequently, AF [26]. Other cardiovascular disease risk factors such as heart failure and valvulopathy were

Table 4 Drugs used by participants and relevant lab results

\begin{tabular}{|c|c|c|c|c|}
\hline Variables & Total N=231 (100.0\%) & AF N = $18(7.8 \%)$ & No AF N = $213(92.2 \%)$ & $p$-value \\
\hline Omeprazole, Yes (\%) & 79 (34.2) & $4(22.2)$ & $75(35.2)$ & 0.392 \\
\hline Lansoprazole, Yes (\%) & $75(32.5)$ & $6(33.3)$ & $69(32.4)$ & 0.935 \\
\hline Beta-blocker, Yes (\%) & $94(40.7)$ & $5(27.8)$ & 89 (41.8) & 0.362 \\
\hline Calcium channel blocker, Yes (\%) & $100(43.3)$ & $4(22.2)$ & $96(45.1)$ & 0.102 \\
\hline ACE inhibitor, Yes (\%) & $10(4.3)$ & $1(5.6)$ & $9(4.2)$ & 0.790 \\
\hline Furosemide, Yes (\%) & $53(22.9)$ & $4(22.2)$ & $49(23.0)$ & 0.940 \\
\hline Calcium carbonate, Yes (\%) & $209(90.5)$ & $16(88.9)$ & $193(90.6)$ & 0.811 \\
\hline Vitamin D, Yes (\%) & $26(11.3)$ & $4(22.2)$ & $22(10.3)$ & 0.252 \\
\hline Erythropoietin, Yes (\%) & $77(33.3)$ & $6(33.3)$ & $71(33.3)$ & 1.000 \\
\hline Alpha 1 hydroxylase vit D, Yes (\%) & $163(70.6)$ & $15(83.3)$ & $148(69.5)$ & 0.333 \\
\hline \multicolumn{5}{|l|}{ Labs } \\
\hline Low haemoglobin (anaemia), Yes (\%) & $21(9.1)$ & $1(5.6)$ & $20(9.4)$ & 0.891 \\
\hline Serum $\mathrm{Ca}^{2+}$, Low (\%) & $76(32.9)$ & $6(33.3)$ & $70(32.9)$ & 0.922 \\
\hline Serum $K^{+}$, Low (\%) & $7(3.0)$ & $2(11.1)$ & $5(2.4)$ & 0.223 \\
\hline Hypoalbuminemia, Yes (\%) & $34(14.7)$ & $2(11.1)$ & $32(15.0)$ & 0.885 \\
\hline
\end{tabular}

$\mathrm{AF}=$ atrial fibrillation; $\mathrm{ACE}=$ Angiotensin converting enzyme 
Table 5 Bivariate and multiple logistic regression analysis of factors associated with subclinical atrial fibrillation

\begin{tabular}{|c|c|c|c|c|}
\hline Variables & OR $(95 \% \mathrm{Cl})$ & $p$-value & Adjusted OR (95\% Cl) & $p$-value \\
\hline \multicolumn{5}{|l|}{ Sociodemographic data } \\
\hline Age in years & $1.07(1.03-1.12)$ & $0.003^{*}$ & $1.05(1.01-1.10)$ & $0.031^{*}$ \\
\hline Gender, Female ${ }^{\&}$ & $1.64(0.86-4.35)$ & 0.323 & & \\
\hline Marital Status, Single & $0.30(0.05-1.08)$ & 0.111 & & \\
\hline Body mass index (BMI) $\left(\mathrm{kg} / \mathrm{m}^{2}\right)$ & $1.00(0.92-1.09)$ & 0.912 & & \\
\hline \multicolumn{5}{|l|}{ Past Medical History } \\
\hline Hypertension, Yes (\%) & $1.70(0.53-7.51)$ & 0.417 & & \\
\hline Diabetes mellitus, Yes (\%) & $2.04(0.77-5.54)$ & 0.151 & & \\
\hline Dyslipidaemia, Yes (\%) & $1.19(0.40-3.21)$ & 0.738 & & \\
\hline Ischemic heart disease, Yes (\%) & $3.44(1.12-9.68)$ & $0.022^{*}$ & $3.74(1.09-12.34)$ & $0.033^{*}$ \\
\hline Heart failure, Yes (\%) & $2.44(0.74-7.02)$ & 0.113 & & \\
\hline Valvulopathy, Yes (\%) & $4.12(0.20-34.20)$ & 0.231 & & \\
\hline Family history of dialysis, Yes (\%) & $0.75(0.17-2.39)$ & 0.655 & & \\
\hline History of smoking, Yes (\%) & $0.19(0.03-0.68)$ & $0.029^{*}$ & $0.15(0.02-0.60)$ & $0.019^{*}$ \\
\hline Consume alcohol, Yes (\%) & $7.31 e-07(\mathrm{NA})$ & 0.989 & & \\
\hline Tea intake, Yes (\%) & & 0.300 & & \\
\hline Number of glasses of tea per week & $1.01(0.97-1.05)$ & 0.522 & & \\
\hline Coffee intake, Yes (\%) & $0.56(0.21-1.60)$ & 0.260 & & \\
\hline Number of cups of coffee per week & $0.95(0.88-1.01)$ & 0.164 & & \\
\hline \multicolumn{5}{|l|}{ Dialysis } \\
\hline Duration of dialysis (in hours) & $0.57(0.20-1.61)$ & 0.292 & & \\
\hline Number of sessions per week & 1.06 e07 (NA) & 0.992 & & \\
\hline \multicolumn{5}{|l|}{ Dialysis access type } \\
\hline Arteriovenous fistula & Ref & & & \\
\hline Arteriovenous graft & 8.57 e-07 (NA) & 0.992 & & \\
\hline Central dialysis catheter & $1.83(0.61-5.00)$ & 0.253 & & \\
\hline \multicolumn{5}{|l|}{ Pre-dialysis } \\
\hline Average systolic BP (in mmHg) & $0.99(0.97-1.01)$ & 0.340 & & \\
\hline Average diastolic BP (in mmHg) & $0.95(0.92-0.99)$ & $0.024^{*}$ & $0.96(0.92-1.00)$ & 0.078 \\
\hline \multicolumn{5}{|l|}{ Post dialysis } \\
\hline Average systolic BP (in mmHg) & $1.00(0.98-1.02)$ & 0.943 & & \\
\hline Average diastolic BP (in mmHg) & $1.00(0.96-1.03)$ & 0.966 & & \\
\hline Average weight gain during dialysis (in kg) & $0.55(0.31-0.94)$ & $0.035^{*}$ & $0.50(0.25-0.91)$ & $0.031^{*}$ \\
\hline \multicolumn{5}{|l|}{ Labs } \\
\hline Low haemoglobin (Anaemia), Yes (\%) & $0.59(0.03-3.13)$ & 0.613 & & \\
\hline Serum calcium, Low (\%) & $0.95(0.32-2.56)$ & 0.922 & & \\
\hline Serum potassium, Low (\%) \& & $0.21(0.04-1.59)$ & 0.081 & & \\
\hline Hypoalbuminemia, Yes (\%) & $1.48(038-9.79)$ & 0.621 & & \\
\hline
\end{tabular}

${ }^{8}$ Excluded during the backward elimination procedure; $\mathrm{BP}=$ Blood pressure; $\mathrm{Cl}=$ confidence interval; $\mathrm{OR}=\mathrm{Odds}$ ratio. Predictive power of final model: Nagelkerke pseudo ${ }^{2}=0.254 ; C$ statistics $=82.2 \%$

Goodness-of-fit: Hosmer-Lemeshow test $\left(X^{2}=3.31, p=0.913\right)$.

not significant in our study $[17,18,20,24]$. This is most likely due to the small number of participants with these comorbidities, Table 2.
The association between cigarette smoking and $\mathrm{AF}$ is controversial. Although a link has been demonstrated between smoking, mostly current smoking and AF in 


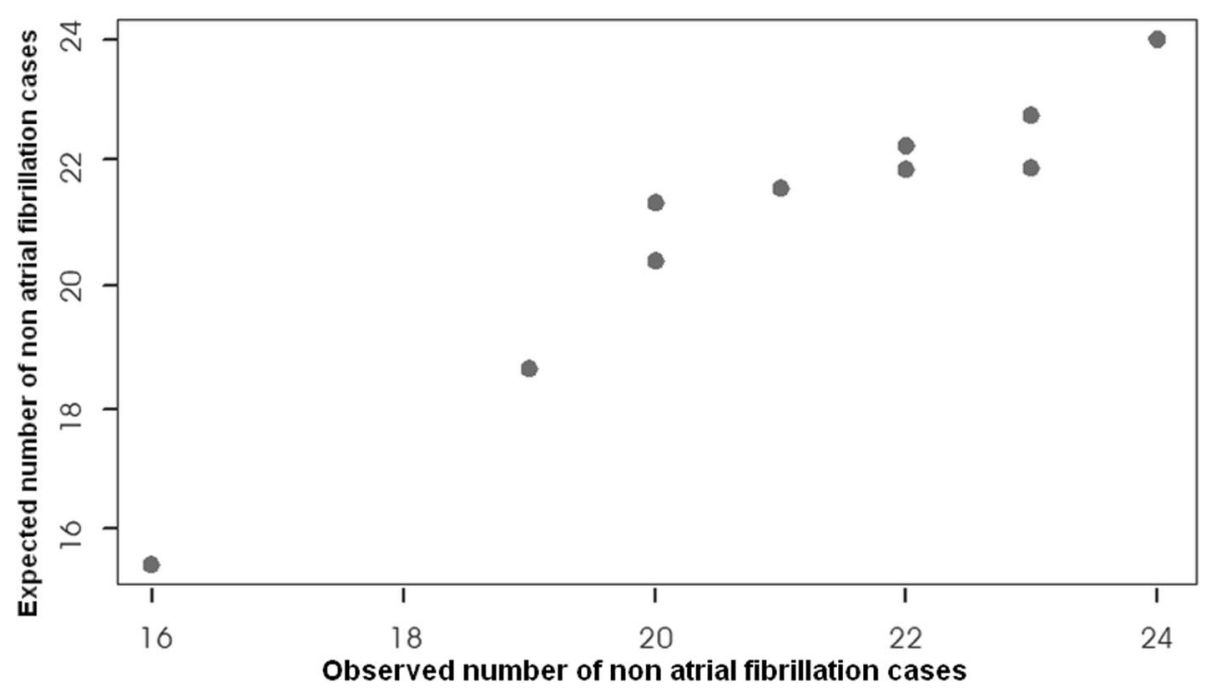

Fig. 1 Observed vs. expected probability of non-atrial fibrillation casesDescription: Hosmer-Lemeshow goodness-of-fit test. The plotted points follow a linear relationship, which testifies a good-fit of the prediction model of data

most part of literature, most studies conducted on ESRD patients on haemodialysis have failed to identify any associations $[17,18,22,25,28]$. Smoking was paradoxically protective against AF in our study. This finding was similar to those of Mariscalco and Engström who reported a protective effect of current smoking among participants who had undergone a coronary artery bypass and valvular surgical procedure [29]. However, a review by D'Alessandro et al. (2011) instead found smoking cessation to be preventive against AF [30]. A possible explanation for this association is that with chronic kidney disease being a chronic inflammatory state, ex-smokers whose cardiomyocytes have been exposed to higher adrenergic states can better tolerate the stress induced by chronic kidney disease and dialysis. However, this association is likely to be more complex and multifactorial, and there warrant further explorations.

Finally, in our study, lower interdialytic weight gain was associated with the occurrence of AF. Traditionally, higher interdialytic weight gain is linked to adverse morbidity and all-cause mortality and has been a growing

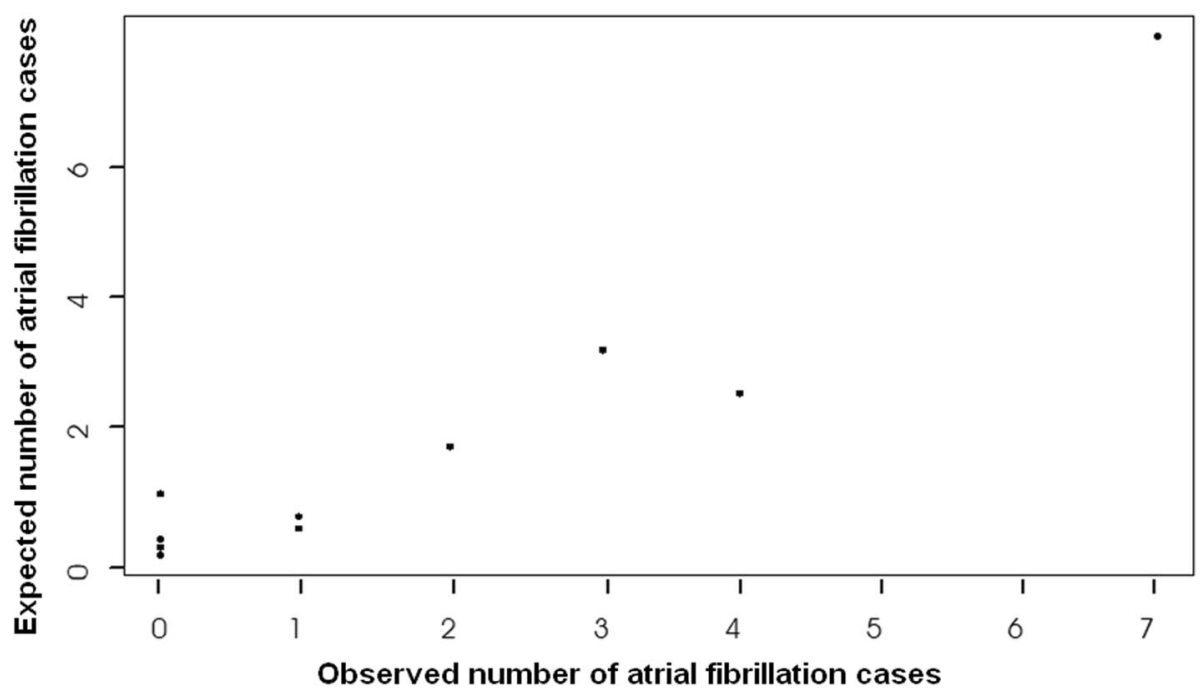

Fig. 2 Observed vs. expected probability of atrial fibrillation casesDescription: Hosmer-Lemeshow goodness-of-fit test. The plotted points follow a linear relationship, which testifies a good-fit of the prediction model of data 
area of interest in dialysis medicine [31-33]. However, the association between interdialytic weight gain and AF is poorly established as this has been poorly studied in literature. Even though increasing interdialytic weight has been associated with cardiovascular morbidity such as ischaemic heart disease [34], little or nothing is known about its association with AF. This association is likely linked to the inverse correlation of interdialytic weight gain with age. That is, patients with higher interdialytic weight gain tend to be younger [31] and less likely to develop $\mathrm{AF}[17,18,20,24]$. Nevertheless, the association between interdialytic weight gain and AF remained true even after controlling for age. In one study, dialysis patients who were hypertensive due to hypervolemic state were found to have lower interdialytic weight gain which may partially explain the higher AF rate in these patients [35]. Additionally, a small group of patients with low interdialytic weight gain, especially those with no residual kidney function, were found to have protein-energy wasting, malnutrition, or intercurrent illness that may explain a higher AF rate [33].

\section{Study limitations}

Although we attained the minimum acceptable required sample size for this study, a larger sample size would have enabled us to detect smaller effects. Smaller sample sizes seem to be a major challenge for studies where data was collected prospectively using a cross-sectional design [18]. Most large-scale studies have been designed as either retrospective (using medical records) or prospective cohort. Also, despite the strict selection criteria including only patients without a prior diagnosis of AF, there is a possibility that we missed cases of paroxysmal AF. This study has several strengths. This is the first study on the subject in Jordan. Also, we established the diagnosis of AF based on recommended criteria. Furthermore, we used recommended and robust analytic techniques to build our regression model to make predictions with very good degree of accuracy.

\section{Conclusions}

The prevalence of subclinical atrial fibrillation among ESRD patients on maintenance dialysis was found to be high and this was mainly driven by advancing age, history of ischaemic heart disease, history of smoking, and lower interdialytic weight gain. ESRD is distinctive in Jordan because it affects mostly younger individuals at the prime of their economic productivity, thereby posing a significant socioeconomic burden. We suggest checking routinely for $\mathrm{AF}$ in patients on haemodialysis and if present to consider anticoagulant therapy as this may prevent serious complications. Finally, more large-scale studies are required on the national territory and the
Middle East region, with the creation of national and regional registries for prospective observations.

\section{Abbreviations}

AF: Atrial fibrillation; Cl: Confidence intervals; OR: Odds ratio; AOR: Adjusted odds ratio; CKD: Chronic kidney disease; ESRD: End stage renal disease; BP: Blood pressure; ECG: Electrocardiogram; SD: Standard deviation; IQR: Interquartile range; AIC: Akaike information criterion; ACE: Angiotensin converting enzyme

\section{Acknowledgements}

We thank Dr. Valirie Agbor for his great assistant in the data analysis and manuscript writing.

\section{Authors' contributions}

IA designed and supervised the study. RA, NA and AO collected the data and entered to the Excel sheets. SI provided statistical advice and performed statistical analysis. IA, RA, NA and SI wrote the first draft of the manuscript. AS accustomed the study design and interpreted the ECGs. SJ recruited and supervised the patients and the study in Al-Essra and Islamic hospitals. AA contributed to literature review and manuscript editing. All co-authors contributed to the data acquisition and interpretation and provided critical feedback on drafts of the manuscript. All authors read and approved the final version of the manuscript.

\section{Funding}

Partial funding was received from the deanship of research of the University of Jordan.

\section{Availability of data and materials}

The datasets used and/or analysed during the current study are available from the corresponding author on reasonable request.

\section{Ethics approval and consent to participate}

The study protocol was approved by the ethical review boards (IRB) of the Jordan University Hospital (Ref: 190/2018), Al-Essra, Al-Bashir, and the Islamic hospitals. All participants signed an informed written consent form after explaining the details of the research, its procedure, potential benefits and harm, and their questions were satisfactorily answered.

\section{Consent for publication}

Not applicable.

\section{Competing interests}

The authors declare that they have no competing interests.

\section{Author details}

${ }^{1}$ School of medicine, the University of Jordan, PO Box 954180, Amman 11954, Jordan. ${ }^{2}$ the University of Jordan, Amman, Jordan. ${ }^{3}$ Al-Essra Hospital, Amman, Jordan. ${ }^{4}$ King Hussein Medical Centre, Amman, Jordan.

Received: 19 June 2019 Accepted: 7 April 2020

Published online: 21 April 2020

\section{References}

1. Chugh SS, Roth GA, Gillum RF, Mensah GA. Global burden of atrial fibrillation in developed and developing nations. Glob Heart. 2014;9:113-9.

2. Noubiap JJ, Bigna JJ, Agbor VN, Mbanga C, Ndoadoumgue AL, Nkeck JR, et al. Meta-Analysis of Atrial Fibrillation in Patients with Various Cardiomyopathies. Am J Cardiol. 2019:S0002914919304679.

3. Agbor VN, Aminde LN, Tianyi F-L, Mbanga CM, Petnga S-JN, Ditah C, et al. Atrial fibrillation among adults with heart failure in sub-Saharan Africa prevalence, incidence and all-cause mortality: a systematic review and meta-analysis protocol. BMJ Open. 2019;9:e022320.

4. Chugh SS, Blackshear JL, Shen W-K, Hammill SC, Gersh BJ. Epidemiology and natural history of atrial fibrillation: clinical implications. J Am Coll Cardiol. 2001;37:371-8.

5. Chugh SS, Havmoeller R, Narayanan K, Singh D, Rienstra M, Benjamin EJ, et al. Worldwide epidemiology of atrial fibrillation. Circulation. 2014 https://doi.org/10.1161/CIRCULATIONAHA.113.005119. 
6. Hill NR, Fatoba ST, Oke JL, Hirst JA, O'Callaghan CA, Lasserson DS, et al. Global prevalence of chronic kidney disease - a systematic review and meta-analysis. PLoS One. 2016;11. https://doi.org/10.1371/journal.pone. 0158765.

7. Gansevoort RT, Correa-Rotter R, Hemmelgarn BR, Jafar TH, Heerspink HJL, Mann JF, et al. Chronic kidney disease and cardiovascular risk: epidemiology, mechanisms, and prevention. Lancet Lond Engl. 2013;382: 339-52.

8. Di Lullo L, House A, Gorini A, Santoboni A, Russo D, Ronco C. Chronic kidney disease and cardiovascular complications. Heart Fail Rev. 2015;20: 259-72.

9. Liu M, Li X-C, Lu L, Cao Y, Sun R-R, Chen S, et al. Cardiovascular disease and its relationship with chronic kidney disease. Eur Rev Med Pharmacol Sci. 2014;18:2918-26.

10. United States Renal Data System. 2014 USRDS annual data report: Epidemiology of kidney disease in the United States. National Institutes of Health, National Institute of Diabetes and Digestive and Kidney Diseases, Bethesda, MD, 2014. https://www.usrds.org/2014/view/. Accessed 29 Apr 2019.

11. Munger MA, Ateshkadi A, Cheung AK, Flaharty KK, Stoddard GJ, Marshall EH. Cardiopulmonary events during hemodialysis: effects of dialysis membranes and dialysate buffers. Am J Kidney Dis Off J Natl Kidney Found. 2000;36: 130-9.

12. Franczyk B, Gluba-Brzózka A, Bartnicki P, Rysz J. The occurrence of atrial fibrillation in dialysis patients and its association with left atrium volume before and after dialysis. Int Urol Nephrol. 2017:49:1071-7.

13. Genovesi S, Fabbrini P, Pieruzzi F, Galbiati E, Sironi E, Pogliani D, et al. Atrial fibrillation in end stage renal disease patients: influence of hemodialysis on P wave duration and atrial dimension. J Nephrol. 2015;28:615-21.

14. Buiten MS, de Bie MK, Rotmans Jl, Gabreëls BA, van Dorp W, Wolterbeek R, et al. The dialysis procedure as a trigger for atrial fibrillation: new insights in the development of atrial fibrillation in dialysis patients. Heart. 2014;100: 685-90.

15. Charytan DM, Foley R, McCullough PA, Rogers JD, Zimetbaum P, Herzog CA, et al. Arrhythmia and sudden death in hemodialysis patients: protocol and baseline characteristics of the monitoring in Dialysis study. Clin J Am Soc Nephrol CJASN. 2016;11:721-34.

16. Verde E. Pérez de Prado a, López-Gómez JM, Quiroga B, Goicoechea M, García-Prieto a, et al. asymptomatic Intradialytic supraventricular arrhythmias and adverse outcomes in patients on hemodialysis. Clin J Am Soc Nephrol CJASN. 2016:11:2210-7.

17. Königsbrügge $O$, Posch F, Antlanger M, Kovarik J, Klauser-Braun R, Kletzmayr $J$, et al. Prevalence of atrial fibrillation and antithrombotic therapy in hemodialysis patients: cross-sectional results of the Vienna InVestigation of AtriaL fibrillation and thromboembolism in patients on HemoDlalysis (VIVALDI). PLoS One. 2017;12:e0169400.

18. Vazquez E, Sanchez-Perales C, Garcia-Garcia F, Castellano P, Garcia-Cortes MJ, Liebana A, et al. Atrial fibrillation in incident dialysis patients. Kidney Int. 2009;76:324-30

19. Bansal N, Fan D, Hsu C, Ordonez JD, Marcus GM, Go AS. Incident atrial fibrillation and risk of end-stage renal disease in adults with chronic kidney disease. Circulation. 2013. https://doi.org/10.1161/CIRCULATIONAHA.112. 123992.

20. Winkelmayer WC, Patrick AR, Liu J, Brookhart MA, Setoguchi S. The increasing prevalence of atrial fibrillation among hemodialysis patients. J Am Soc Nephrol JASN. 2011;22:349-57.

21. Genovesi S, Vincenti A, Rossi E, Pogliani D, Acquistapace I, Stella A, et al. Atrial fibrillation and morbidity and mortality in a cohort of long-term hemodialysis patients. Am J Kidney Dis. 2008;51:255-62.

22. Wizemann V, Tong L, Satayathum S, Disney A, Akiba T, Fissell RB, et al. Atrial fibrillation in hemodialysis patients: clinical features and associations with anticoagulant therapy. Kidney Int. 2010;77:1098-106.

23. Heinze $G$, Wallisch C, Dunkler D. Variable selection - a review and recommendations for the practicing statistician. Biom J Biom Z. 2018;60: 431-49.

24. Wasmer K, Eckardt L, Breithardt G. Predisposing factors for atrial fibrillation in the elderly. J Geriatr Cardiol JGC. 2017;14:179-84.

25. Benjamin EJ, Levy D, Vaziri SM, D'Agostino RB, Belanger AJ, Wolf PA Independent risk factors for atrial fibrillation in a population-based cohort. Framingham Heart Study JAMA. 1994:271:840-4.
26. Lau DH, Schotten U, Mahajan R, Antic NA, Hatem SN, Pathak RK, et al. Novel mechanisms in the pathogenesis of atrial fibrillation: practical applications. Eur Heart J. 2016;37:1573-81.

27. Brandes A. Smit MD. Rienstra M, Gelder ICV. Risk Factor Management in Atrial Fibrillation. J - Risk Factor Manag Atr Fibrillation: Nguyen BO; 2018 https://www.aerjournal.com/articles/risk-factor-management-atrial-fibrillation.

28. Watanabe I. Smoking and risk of atrial fibrillation. J Cardiol. 2018;71:111-2.

29. Mariscalco G, Engström KG. Are current smokers paradoxically protected against atrial fibrillation after cardiac surgery? Nicotine Tob Res Off J Soc Res Nicotine Tob. 2009:11:58-63.

30. D'Alessandro A, Boeckelmann I, Hammwhöner M, Goette A. Nicotine, cigarette smoking and cardiac arrhythmia: an overview. Eur J Prev Cardiol. 2012;19:297-305.

31. Ipema KJR, Kuipers J, Westerhuis R, Gaillard CAJM, van der Schans CP. Krijnen WP, et al. Causes and consequences of Interdialytic weight gain. Kidney Blood Press Res. 2016;41:710-20.

32. Turakhia MP, Blankestijn PJ, Carrero J-J, Clase CM, Deo R, Herzog CA, et al. Chronic kidney disease and arrhythmias: conclusions from a kidney disease: improving global outcomes (KDIGO) controversies conference. Eur Heart J. 2018:39:2314-25.

33. Wong MMY, McCullough KP, Bieber BA, Bommer J, Hecking M, Levin NW, et al. Interdialytic weight gain: trends, predictors, and associated outcomes in the international Dialysis outcomes and practice patterns study (DOPPS). Am J Kidney Dis Off J Natl Kidney Found. 2017;69:367-79.

34. Cabrera C, Brunelli SM, Rosenbaum D, Anum E, Ramakrishnan K, Jensen DE, et al. A retrospective, longitudinal study estimating the association between interdialytic weight gain and cardiovascular events and death in hemodialysis patients. BMC Nephrol. 2015;16:113.

35. Sinha AD, Agarwal R. What are the causes of the ill effects of chronic hemodialysis? The fallacy of low interdialytic weight gain and low ultrafiltration rate: lower is not always better. Semin Dial. 2014;27(1):11-3. https://doi.org/10.1111/sdi.12151.

\section{Publisher's Note}

Springer Nature remains neutral with regard to jurisdictional claims in published maps and institutional affiliations.

Ready to submit your research? Choose BMC and benefit from

- fast, convenient online submission

- thorough peer review by experienced researchers in your field

- rapid publication on acceptance

- support for research data, including large and complex data types

- gold Open Access which fosters wider collaboration and increased citations

- maximum visibility for your research: over $100 \mathrm{M}$ website views per year

At $\mathrm{BMC}$, research is always in progress.

Learn more biomedcentral.com/submissions 